\title{
Incidence of fatalities of road traffic accidents associated with alcohol consumption and the use of psychoactive drugs: A 7-year survey (2011-2017)
}

\author{
ATHANASIA H. PAPALIMPERI, SOTIRIOS A. ATHANASELIS, ARETI D. MINA, \\ IOANNIS I. PAPOUTSIS, CHARAA. SPILIOPOULOU and STAVROULA A. PAPADODIMA \\ Department of Forensic Medicine and Toxicology, School of Medicine, \\ National and Kapodistrian University of Athens, 11527 Athens, Greece
}

Received June 3, 2019; Accepted July 15, 2019

DOI: $10.3892 /$ etm.2019.7787

\begin{abstract}
Driving under the influence of alcohol and/or psychoactive substances increases the risk of severe, even fatal motor vehicle accidents. The aim of this descriptive study was to present the impact of alcohol and/or psychoactive substances on fatal road traffic accidents (RTAs) during the period 2011-2017. For this purpose, the toxicological investigation reports from the Department of Forensic Medicine and Toxicology of the University of Athens were used. In total, 1,841 (32.2\%) of the autopsies conducted by the Department of Forensic Medicine and Toxicology of the National and Kapodistrian University of Athens over a 7-year period (2011-2017) were victims of fatal RTAs. Blood and urine samples were collected and analyzed for the presence of alcohol and psychoactive substances. The results were classified according to sex, age, victim (car driver, motorcyclist, pedestrian, or passenger) and the date the accident occurred (day, month and year). In total, $40.7 \%$ of the RTA-related fatalities were associated with alcohol consumption, among which $20.3 \%$ were car drivers. Of these, $87.3 \%$ were male victims. A higher frequency of RTA-related fatalities associated with a blood alcohol concentration (BAC) $>110 \mathrm{mg} / \mathrm{dl}$ was encountered in younger compared with older age groups. Psychoactive substances were detected in $348(18.9 \%)$ of the victims (cannabis in $46.6 \%$ of these, benzodiazepines in $25.9 \%$, opiates in $16.4 \%$ and cocaine in $11.1 \%$ of these). The percentage of the RTA-related victims that had consumed alcohol in combination with other psychoactive substances was $4.5 \%$. On the whole, the findings of this study suggest that alcohol and psychoactive substances are probably risk factors for RTA-related fatalities.
\end{abstract}

Correspondence to: Dr Athanasia H. Papalimperi, Department of Forensic Medicine and Toxicology, School of Medicine, National and Kapodistrian University of Athens, M. Asias 75, Goudi, 11527 Athens, Greece

E-mail: a.papa007@hotmail.com

Key words: alcohol, psychoactive drugs, traffic accidents, fatalities

\section{Introduction}

Alcohol (ethanol) is a widespread euphoriant and acts as a central nervous system depressant. It is absorbed from the gastrointestinal tract and the rate of absorption depends on the amount consumed, the concentration of ethanol in the drink, the interaction with medicinal drugs, the presence of food in the stomach and the duration of the digestion process. Following absorption, approximately $95 \%$ of ethanol is metabolized in the liver and excreted in urine, and $5 \%$ is excreted, without undergoing metabolism, through the lungs, urine or sweat. The effects of ethanol's action on the central nervous system include cognitive, judgment and memory impairment, relaxation, sensory dysfunction (e.g., balance, speech, vision, reaction time and hearing) and motor impairment. In addition, alcohol consumption at high concentrations (binge drinking) may cause vomiting, amnesia or even death (1).

Alcohol is positively associated with increased morbidity and mortality in a number of diseases and violent injuries among which road traffic accidents (RTAs) are present at a high ranking status (2). Canada, the United States of America (USA) and New Zealand are, in turn, the 3 top countries globally with the highest percentage of RTA-related fatalities associated with alcohol consumption (3). In the European Union, alcohol is one out of the 3 main risk factors accountable for $40 \%$ of poor health and premature deaths. Globally, RTA-related injuries are the leading cause of mortality among teenagers and young adults (aged between 15 and 29 years) (3), which highlights driving under the influence of alcohol as a major risk factor for the demographic and socioeconomic status of any country. In 2012, the age-standardized death rates (ASDR) of alcohol-related RTAs in Greece was estimated to 31.5/100000 individuals (4).

Previous studies, such as those conducted in Finland (5), Mexico (6) and South Africa (7), have verified that driving under the influence of alcohol impairs attention and cognitive capacities. According to Sauber-Schatz et al (8), in the USA and 19 other high-income countries, driving under the influence of alcohol is often associated with the absence of the use of seatbelts, something that increases the risk of injuries. In Thailand, Tongklao et al (9) demonstrated that alcohol consumption was associated with 
the absence of the use of driving helmets, while in the United Kingdom, Clarke et al (10) associated alcohol-impaired driving with driving at high speeds. Furthermore, fatal alcohol-related RTAs among vulnerable road users (pedestrians or cyclists) is a significant issue in a number of countries, such as in Canada (11), Scotland (12) and SriLanka (13).

Driving under the influence of drugs is also considered a serious issue affecting public health. Li et al (14) and Romano et al (15) in the USA, Simonsen et al (16) in Denmark, Imad et al (17) in Jordan, Gadegbeku et al (18) and Martin et al (19) in France, Veldstra et al (20) in The Netherlands and Brubacher et al (21) in the United Kingdom also indicated that the combination of alcohol consumption and the use of psychoactive substances was associated with an increased risk of a fatal RTA.

In Greece, previous studies have highlighted the role of alcohol consumption and the use of psychoactive substances in RTA-related fatalities. During the period between 1995-1997, $41 \%$ of the drivers involved in traffic accidents were found to be positive for alcohol consumption (22). During the period between 1998-2004, male drivers aged between 20 and 40 years were found more likely to be involved in alcohol-related RTAs (23). In Athens, the capital of Greece, almost a third of RTA-related fatalities have been found to be associated with the use of alcohol, psychoactive drugs or both (24). In addition, in a 3-year study (2006-2008) (25) in the region of Central Macedonia, it was observed that alcohol was detected in $28 \%$ of the drivers involved in a fatal collision.

The objective of this study was to present the current situation concerning the involvement of alcohol and other psychoactive substances in fatal RTAs over a 7-year period (2011-2017) in Greece. For this purpose, the results of the toxicological investigations from the database of the Department of Forensic Medicine and Toxicology of the National and Kapodistrian University of Athens were retrieved and evaluated according to the blood alcohol concentration (BAC), the presence of psychoactive substances, the victim (car driver, motorcyclist, pedestrian, or passenger), the sex and age of the victims of the RTAs, and the date the accident occurred (day, month and year).

\section{Subjects and methods}

The Department of Forensic Medicine and Toxicology of the National and Kapodistrian University of Athens is authorized to perform the toxicological investigation of traffic accidents that occur in the major part of the country. A total of 5,716 autopsies were conducted between January, 2011 and December, 2017. Of these, 1,841 (32.2\%) were RTA-related fatalities. The victims included car drivers, motorcyclists, passengers and pedestrians. The results were classified according to sex, age and the type of victims, as well as the day, the month and year, on which the accident occurred.

Toxicological investigation was performed according to the Greek legislation (Ministerial Decision No. 2500/15/135, Greek Government Gazette B 2077 of September 19, 2011). The results of the toxicological analyses were classified according to the BAC and the category of the psychoactive substance detected. Alcohol analysis was performed in whole blood samples using a headspace-gas chromatography-flame ionization detector (HS-GC-FID) method (26). Psychoactive

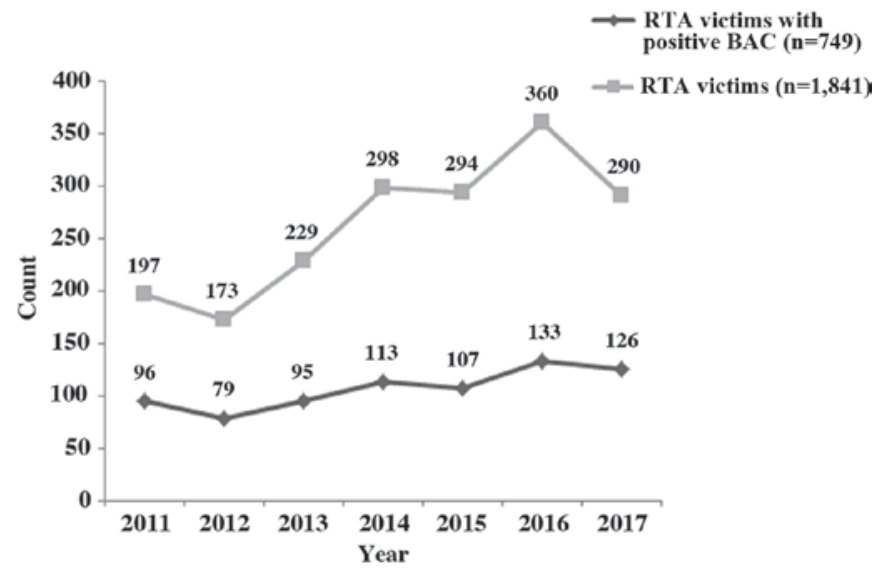

Figure 1. Victims of RTAs and victims of RTAs who were BAC-positive by year. RTAs, road traffic accidents; BAC, blood alcohol concentration.

substances were detected in blood and urine samples using a screening immunochemical method (VIVA-E, Siemens). Their presence in the blood was confirmed by validated in house gas chromatography/mass spectrometry (GC/MS) methods. BACs were classified according to the limits dictated by the Greek Road Traffic Code where the maximum permitted level of alcohol in blood is $50 \mathrm{mg} / \mathrm{dl}$.

\section{Results}

The highest percentage of fatal RTA-related victims was observed in $2016(n=360,19.5 \%)$, followed by $2014(n=298$, 16.2\%), $2015(\mathrm{n}=294,16 \%)$ and $2017(\mathrm{n}=290,15.8 \%)$ (Fig. 1). A total of $79.2 \%(n=1,458)$ of the RTA-related victims were male and $20.8 \%(n=383)$ were female, respectively. In 1,371 cases $(74.5 \%)$, the victims were car drivers and motorcyclists. The majority of the victims were car drivers $(43.2 \%, n=795)$, and predominantly individuals aged between 21 and 30 years (20.3\%, n=373) (Table I). Accordingly, young individuals (aged 21-30 years) were over-represented among the fatally-injured motorcyclists (142 out of 576 cases, 24.7\%) and passengers (44 out of 162 cases, $27.2 \%$ ), as presented in Table I. On the other hand, the majority of fatally-injured pedestrians (175 out of 308 cases, $56.8 \%$ ) were over 71 years of age (Table I).

Alcohol was detected in $40.7 \%(n=749)$ of the RTA-related victims (Fig. 1). Of these, $464(61.9 \%)$ had consumed alcohol alone, while the rest had consumed alcohol in combination with at least one psychoactive drug (data not shown). In total, $87.3 \%(n=654)$ of the RTA-related victims who were alcohol-positive were male and $12.7 \%(n=95)$ female victims, respectively. A total of 373 of the RTA-related fatalities who were alcohol-positive (20.3\%) were car drivers and the majority of the victims of alcohol-related RTAs were male car drivers and motorcyclists ( $\mathrm{n}=557,74.4 \%$ ) (Fig. 2). Additionally, 55.7\% $(n=417)$ of the victims of alcohol-related RTAs were found with a BAC $>110 \mathrm{mg} / \mathrm{dl}$ and were mostly male (Table II).

Young drivers (21-30 years of age) driving under the influence of alcohol were more often involved in fatal RTAs than drivers of other ages (Fig. 3). The percentage of RTA-related fatalities associated with alcohol consumption was higher in the 21-30-year age group compared to the other age groups (Table III). 
Table I. Victims of RTAs by sex, type and age group.

\begin{tabular}{|c|c|c|c|c|c|c|c|c|c|}
\hline \multirow[b]{2}{*}{ Type and sex } & \multicolumn{9}{|c|}{ Age group (years) } \\
\hline & $18-20$ & $21-30$ & $31-40$ & $41-50$ & $51-60$ & $61-70$ & $71-80$ & $>80$ & Total \\
\hline \multicolumn{10}{|l|}{ Car drivers } \\
\hline \multicolumn{10}{|l|}{ Male } \\
\hline $\mathrm{n}$ & 37 & 131 & 120 & 95 & 92 & 91 & 80 & 37 & 683 \\
\hline$\%$ & 5.4 & 19.2 & 17.6 & 13.9 & 13.5 & 13.3 & 11.7 & 5.4 & 100.0 \\
\hline \multicolumn{10}{|l|}{ Female } \\
\hline $\mathrm{n}$ & 4 & 26 & 26 & 13 & 12 & 14 & 8 & 9 & 112 \\
\hline$\%$ & 3.6 & 23.2 & 23.2 & 11.6 & 10.7 & 12.5 & 7.1 & 8.0 & 100.0 \\
\hline \multicolumn{10}{|l|}{ Motocyclists } \\
\hline \multicolumn{10}{|l|}{ Male } \\
\hline $\mathrm{n}$ & 45 & 127 & 95 & 85 & 80 & 46 & 25 & 25 & 528 \\
\hline$\%$ & 8.5 & 24.1 & 18.0 & 16.1 & 15.2 & 8.7 & 4.7 & 4.7 & 100.0 \\
\hline \multicolumn{10}{|l|}{ Female } \\
\hline $\mathrm{n}$ & 3 & 15 & 13 & 2 & 8 & 4 & 2 & 1 & 48 \\
\hline$\%$ & 6.3 & 31.3 & 27.1 & 4.2 & 16.7 & 8.3 & 4.2 & 2.1 & 100.0 \\
\hline \multicolumn{10}{|l|}{ Pedestrians } \\
\hline \multicolumn{10}{|l|}{ Male } \\
\hline $\mathrm{n}$ & 5 & 13 & 18 & 8 & 16 & 8 & 46 & 56 & 170 \\
\hline$\%$ & 2.9 & 7.6 & 10.6 & 4.7 & 9.4 & 4.7 & 27.1 & 32.9 & 100.0 \\
\hline \multicolumn{10}{|l|}{ Female } \\
\hline $\mathrm{n}$ & 3 & 17 & 5 & 9 & 14 & 17 & 42 & 31 & 138 \\
\hline$\%$ & 2.2 & 12.3 & 3.6 & 6.5 & 10.1 & 12.3 & 30.4 & 22.5 & 100.0 \\
\hline \multicolumn{10}{|l|}{ Passengers } \\
\hline \multicolumn{10}{|l|}{ Male } \\
\hline $\mathrm{n}$ & 14 & 17 & 15 & 4 & 8 & 10 & 3 & 6 & 77 \\
\hline$\%$ & 18.2 & 22.1 & 19.5 & 5.2 & 10.4 & 13.0 & 3.9 & 7.8 & 100.0 \\
\hline \multicolumn{10}{|l|}{ Female } \\
\hline $\mathrm{n}$ & 4 & 27 & 10 & 8 & 12 & 10 & 9 & 5 & 85 \\
\hline$\%$ & 4.7 & 31.4 & 11.6 & 9.3 & 14.0 & 11.6 & 10.5 & 5.8 & 100.0 \\
\hline
\end{tabular}

RTAs, road traffic accidents.

Table II. Blood alcohol concentration by sex in victims of RTAs who were alcohol-positive.

\begin{tabular}{lrrrrr}
\hline & \multicolumn{3}{c}{ Male } & & \multicolumn{2}{c}{ Female } \\
\cline { 2 - 3 } \cline { 5 - 6 } $\begin{array}{l}\text { Blood alcohol } \\
\text { concentration }\end{array}$ & $\mathrm{n}$ & $\%$ & & $\mathrm{n}$ & $\%$ \\
\hline$<50 \mathrm{mg} / \mathrm{dl}$ & 164 & 25.1 & & 48 & 50.5 \\
$50-80 \mathrm{mg} / \mathrm{dl}$ & 48 & 7.3 & & 13 & 13.7 \\
$80-110 \mathrm{mg} / \mathrm{dl}$ & 55 & 8.4 & 4 & 4.2 \\
$>110 \mathrm{mg} / \mathrm{dl}$ & 387 & 59.2 & 30 & 31.6 \\
Total & 654 & 87.3 & 95 & 12.7 \\
\hline
\end{tabular}

RTAs, road traffic accidents.

Alcohol was detected in 44\% (603 out of 1,371 cases who were car drivers and motorcyclists) of drivers involved in
RTAs. In addition, $42.3 \%$ of the fatally injured pedestrians in alcohol-related RTAs were aged over 71 years (Fig. 3).

As regards the seasonality of fatal RTAs, these occurred more often during the summer months (June to August), while $38 \%$ occurred over the weekend (data not shown). Psychoactive substances were detected in 348 cases $(18.9 \%)$ [cannabis in $46.6 \%(n=162)$ of these, benzodiazepines in $25.9 \%(n=90)$, opiates in $16.4 \%(n=57)$ and cocaine in $11.1 \%$ $(n=39)]$. Of these, $91.4 \%(n=318)$ were males and $8.6 \%(n=30)$ were females, as shown in Table IV. The age groups of 21-30 years and 31-40 years presented a higher percentage of cannabis use $[16.7 \%(n=58), 11.5 \%(n=40)$, respectively] than other substances and the age group of 41-50 years had a higher percentage of benzodiazepines use $(8.9 \%, \mathrm{n}=31)$ (Table IV).

Benzodiazepines, cocaine and opioids were detected more frequently in car drivers, while cannabis was detected more often in motorcyclists (Fig. 4). In total, 59 (3.2\%), 39 (2.2\%), $12(0.6 \%)$ and $2(0.1 \%)$ of the victims had used cannabis, benzodiazepines, opioids and cocaine alone, respectively (data 
Table III. Blood alcohol concentration by age group in positive alcohol RTAs victims.

\begin{tabular}{|c|c|c|c|c|c|c|c|c|}
\hline \multirow[b]{3}{*}{ Age group (years) } & \multicolumn{8}{|c|}{ Blood alcohol concentration } \\
\hline & \multicolumn{2}{|c|}{$<50 \mathrm{mg} / \mathrm{dl}$} & \multicolumn{2}{|c|}{$50-80 \mathrm{mg} / \mathrm{dl}$} & \multicolumn{2}{|c|}{$80-110 \mathrm{mg} / \mathrm{dl}$} & \multicolumn{2}{|c|}{$>110 \mathrm{mg} / \mathrm{dl}$} \\
\hline & $\mathrm{n}$ & $\%$ & $\mathrm{n}$ & $\%$ & $\mathrm{n}$ & $\%$ & $\mathrm{n}$ & $\%$ \\
\hline $18-20$ & 12 & 6.2 & 5 & 8.2 & 9 & 12.7 & 27 & 6.4 \\
\hline $21-30$ & 47 & 24.2 & 22 & 36.1 & 20 & 28.2 & 116 & 27.4 \\
\hline $31-40$ & 30 & 15.5 & 6 & 9.8 & 8 & 11.3 & 94 & 22.2 \\
\hline $41-50$ & 21 & 10.8 & 3 & 4.9 & 15 & 21.1 & 86 & 20.3 \\
\hline $51-60$ & 19 & 9.8 & 8 & 13.1 & 11 & 15.5 & 58 & 13.7 \\
\hline $61-70$ & 19 & 9.8 & 10 & 16.4 & 1 & 1.4 & 28 & 6.6 \\
\hline $71-80$ & 25 & 12.9 & 5 & 8.2 & 4 & 5.6 & 9 & 2.1 \\
\hline$>80$ & 21 & 10.8 & 2 & 3.3 & 3 & 4.2 & 5 & 1.2 \\
\hline Total & 194 & 100.0 & 61 & 100.0 & 71 & 100.0 & 423 & 100.0 \\
\hline
\end{tabular}

RTAs, road traffic accidents.

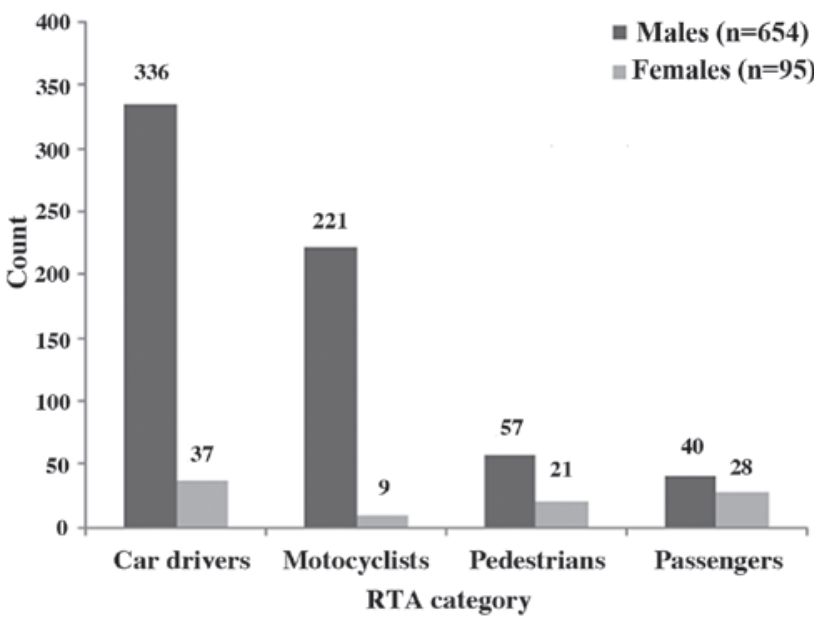

Figure 2. Victims of RTAs who were alcohol-positive by type and sex. RTAs, road traffic accidents.

not shown). The percentage of victims under the influence of alcohol in combination with other psychoactive substances was estimated at $4.5 \%(\mathrm{n}=83)$ (data not shown). In total, $54(2.9 \%), 14(0.7 \%), 11(0.5 \%)$ and $3(0.2 \%)$ of the victims had used alcohol in combination with cannabis, benzodiazepines, cocaine and metabolites of heroin, respectively (data not shown).

\section{Discussion}

In this study, alcohol was detected in $40.7 \%$ of the RTA-related victims and $44 \%$ of the drivers were found to be positive for alcohol use. According to previous studies conducted in Greece $(22,23)$, during the period between 1995-1997 and 1998-2004, drivers involved in alcohol-related RTAs were 37 and $41 \%$, respectively. In addition, the majority of BAC-positive fatalities were car drivers and motorcyclists, in accordance to the findings of Hamnett et al (12) in Scotland and those of Costa et al (27) in Portugal. Papadopoulos et al (24) reported

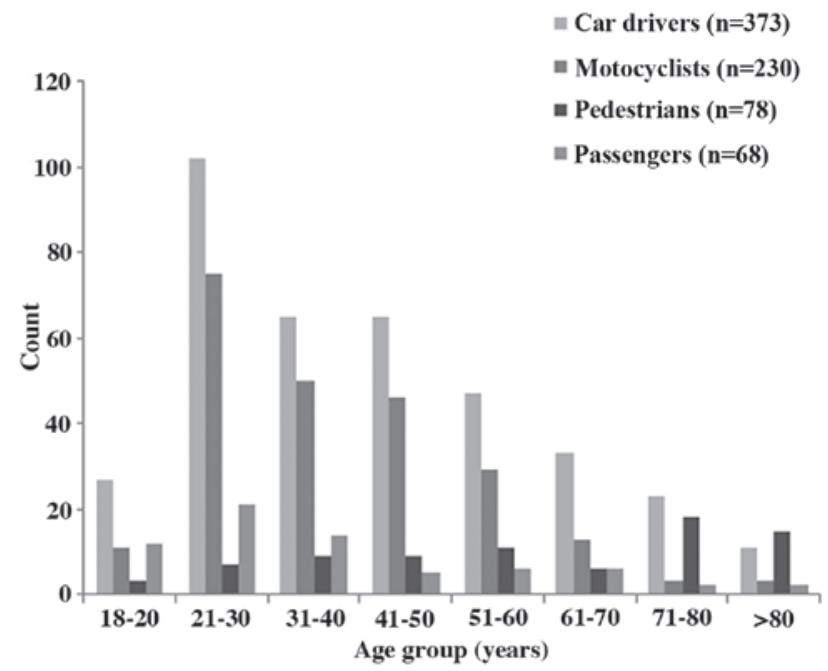

Figure 3. Victims of RTAs who were alcohol-positive by age group. RTAs, road traffic accidents.

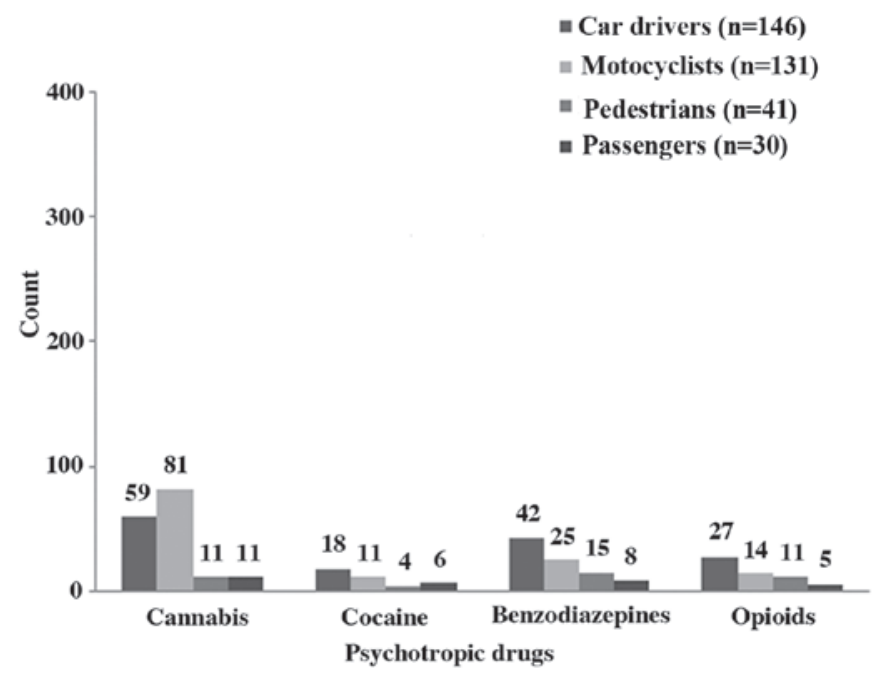

Figure 4. Psychotropic drugs detected in victims of RTAs. RTAs, road traffic accidents. 
Table IV. Psychoactive substances in victims of RTAs by sex and age group.

\begin{tabular}{|c|c|c|c|c|c|c|c|c|c|}
\hline \multirow{2}{*}{$\begin{array}{l}\text { Psychoactive substances } \\
\text { and sex }\end{array}$} & \multicolumn{9}{|c|}{ Age group (years) } \\
\hline & $18-20$ & $21-30$ & $31-40$ & $41-50$ & $51-60$ & $61-70$ & $71-80$ & $>80$ & Total \\
\hline \multicolumn{10}{|l|}{ Cannabis } \\
\hline \multicolumn{10}{|l|}{ Male } \\
\hline $\mathrm{n}$ & 20 & 53 & 35 & 20 & 8 & 9 & 2 & 1 & 148 \\
\hline$\%$ & 12.3 & 32.7 & 21.6 & 12.3 & 4.9 & 5.6 & 1.2 & 0.6 & 91.4 \\
\hline \multicolumn{10}{|l|}{ Female } \\
\hline $\mathrm{n}$ & 2 & 5 & 5 & 1 & 1 & 0 & 0 & 0 & 14 \\
\hline$\%$ & 1.2 & 3.1 & 3.1 & 0.6 & 0.6 & 0.0 & 0.0 & 0.0 & 8.6 \\
\hline \multicolumn{10}{|l|}{ Cocaine } \\
\hline \multicolumn{10}{|l|}{ Male } \\
\hline $\mathrm{n}$ & 3 & 12 & 7 & 5 & 1 & 2 & 2 & 1 & 33 \\
\hline$\%$ & 7.7 & 30.8 & 17.9 & 12.8 & 2.6 & 5.1 & 5.1 & 2.6 & 84.6 \\
\hline \multicolumn{10}{|l|}{ Female } \\
\hline $\mathrm{n}$ & 1 & 1 & 1 & 1 & 2 & 0 & 0 & 0 & 6 \\
\hline$\%$ & 2.6 & 2.6 & 2.6 & 2.6 & 5.1 & 0.0 & 0.0 & 0.0 & 15.4 \\
\hline \multicolumn{10}{|l|}{ Benzodiazepines } \\
\hline \multicolumn{10}{|l|}{ Male } \\
\hline $\mathrm{n}$ & 8 & 10 & 19 & 30 & 4 & 9 & 2 & 1 & 83 \\
\hline$\%$ & 8.9 & 11.1 & 21.1 & 33.3 & 4.4 & 10.0 & 2.2 & 1.1 & 92.2 \\
\hline \multicolumn{10}{|l|}{ Female } \\
\hline $\mathrm{n}$ & 1 & 1 & 1 & 1 & 2 & 1 & 0 & 0 & 7 \\
\hline$\%$ & 1.1 & 1.1 & 1.1 & 1.1 & 2.2 & 1.1 & 0.0 & 0.0 & 7.8 \\
\hline \multicolumn{10}{|l|}{ Opioids } \\
\hline \multicolumn{10}{|l|}{ Male } \\
\hline $\mathrm{n}$ & 4 & 10 & 15 & 19 & 1 & 2 & 2 & 1 & 54 \\
\hline$\%$ & 7.0 & 17.5 & 26.3 & 33.3 & 1.8 & 3.5 & 3.5 & 1.8 & 94.7 \\
\hline \multicolumn{10}{|l|}{ Female } \\
\hline $\mathrm{n}$ & 1 & 1 & 1 & 0 & 0 & 0 & 0 & 0 & 3 \\
\hline$\%$ & 1.8 & 1.8 & 1.8 & 0.0 & 0.0 & 0.0 & 0.0 & 0.0 & 5.3 \\
\hline
\end{tabular}

RTAs, road traffic accidents.

that the majority of BAC-positive RTA-related fatalities were motorcyclists in Athens, Greece. This finding is expected, as many individuals in Athens prefer to use motorcycles for transport in order to avoid traffic congestion.

The present study revealed that the most active and productive age group (21-30 years old) were the most common victims of RTA-related fatalities associated with alcohol consumption. Accordingly, Papadodima et al (23), in a 7-year study (1998-2004) conducted in Greece, reported that the majority of drivers involved in fatal alcohol related traffic accident were young drivers.

In this study, fatal alcohol-related RTAs more often occurred during weekends and the summer period than during weekdays. These results are in accordance with those presented in the study by Ampanozi et al (25) in the region of Central Macedonia, Greece, and with those of Anowar et al (28) in Canada. Weekends were characterized by a higher prevalence of driving under the influence of alcohol, driving under the use of drugs and driver fatigue-related RTAs, as presented in the studies by Foster et al (29) in Switzerland and Furr-Holden et al (30) in the USA. According to EU road safety statistics for 2017, holiday seasons (July and August) are associated with a higher incidence of fatal RTAs than other periods of the year (31). Odero et al (32) reviewed all the published and unpublished reports on RTAs in developing countries from 1966 to May, 1994 and reported that in 79\% of the studies, collisions occurred between Friday and Monday.

In the present study, cannabis, benzodiazepines, opiates and cocaine were detected in 162 cases (8.8\%), 90 cases $(4.9 \%), 57$ cases $(3.1 \%)$ and 39 cases $(2.1 \%)$ of the victims of RTAs, respectively. The percentage of victims driving under the influence of alcohol in combination with other psychoactive substances was estimated at $4.5 \%$. Other studies conducted in the USA (14,33), Norway (34) and Brazil (35) reported that driving under the influence of alcohol or drugs poses a significant issue. The frequency and category of the detected psychoactive substances is variable among countries, as the profile of the drug victim in each country differs and 
depends on the socioeconomic status, the policy that each country enforces regarding alcohol consumption and the use of prescription and illicit drugs. According to the World Drug Report (2018), in 2016, the use of cannabis, opiates, amphetamines and prescription stimulants was predominant in Asia, the use of cocaine in Europe and the use of opiates in America (36). Moreover, male victims presented with a higher percentage of psychoactive substance use compared to female victims, in accordance to the study by Gjerde et al (37) in Norway.

The results of the present study revealed that 1,371 cases of RTA-related fatalities during the period between 2011-2017 were drivers (car drivers and motorcyclists). Papadodima et al (23) reported that during the period between 1998-2004 in Greece, a much higher number (3,167 drivers) of drivers was involved in a fatal traffic accident. This noticeable reduction in RTAs in our country over the past decade may be attributed to the upgrade of country's road network and the development of new and more sophisticated car technologies. It should be noted that the economic crisis in Greece resulted in a reduction in the number of fatal RTAs. This was also observed in Great Britain during the period between 2007-2010 (38). Furthermore, the construction of the Athens Metro (suburban railway) in the year 2000 in Athens contributed significantly to the improvement of the city's traffic circulation and motivated many individuals not to use their own vehicle for transportation.

This study indicated that $43.2 \%$ of the victims of RTAs were car drivers, in accordance with the study by Gopaul et al (39) in Trinidad. Previous studies conducted in other countries, such as in the Ivory Coast (40), China (41), Russia (42) and Pakistan (43) have reported that pedestrians have a higher incidence of traffic accident mortalities. Those differences among countries may be attributed to the predominant types of transportation, economic status, proper infrastructure for pedestrians and cultural awareness. For example, in the African Region, individuals prefer walking and cycling, while in the South-East Asia Region and the Western Pacific Region, individuals mainly used motorcycles as a method of transportation (3).

The findings of this study demonstated that young males were over-represented in fatal road traffic accidents, in accordance with the studies by Ramadani et al (44) in Kosovo, Majdan et al (45) in Austria and Reddy et al (46) in India. Other studies have investigated the reasons for the high occurrence of deaths of young individuals involved in RTAs. In the USA, Lambert-Bélanger et al (47) revealed that aggressive driving constituted a high risk factor of fatal RTAs in young individuals and Weiss et al (48) in New Zealand, reported that rarely or not wearing a seatbelt at all led to road traffic-related deaths among individuals aged between 15-24 years. Furthermore, according to the study by Khadem-Rezaiyan et al (49) in Iran, using a cell phone while driving is a major high-risk behavior of individuals aged $30 \pm 13$ years. Finally, Abayomi et al (50) in Nigeria, and Hingson et al (51) in the USA, reported that driving under the influence of alcohol was responsible for the incidence of fatal RTAs among young individuals.

On the other hand, this study reported that elderly individuals present the majority of fatally injured pedestrians. Accordingly, Kaimila et al (52) in Japan, and Rolison et al (53) in the United Kingdom, reported that elderly pedestrians were more susceptible to road traffic accidents when compared to younger individuals. According to the studies by Zito et al (54) in Switzerland, Cicchino and McCartt (55) and Doroudgar et al (56) in the USA, the main cause seemed to be a consequence of the aging process, which leads to a decrease in balance, hearing, vision, reaction time, muscle mass and bone mass in older individuals.

A limitation of the present study was that victims $<18$ years of age were excluded. In addition, no statistical analysis was performed in this study to determine statistical significance. Thus, further studies are required in order to better determine the significance of the role of alcohol and psychoactive substances in RTAs in Greece.

In conclusion, the present descriptive study presents the impact of alcohol consumption and the use of psychoactive substances in fatal RTAs in Greece. Driving under the influence of alcohol and/or psychoactive substances is associated with careless driving, which could lead to fatal results. Appropriate countermeasures are imperative in order to reduce fatal collisions involving young individuals, including driving simulator training, the development of novel interventions within the field of driving and a more educational approach on driving safety focusing on social networking. Furthermore, it is necessary that state authorities plan educational campaigns and advertisements highlighting the harmful effects of alcohol use and/or other psychoactive substances use while driving.

\section{Acknowledgements}

Not applicable.

\section{Funding}

No funding was received.

\section{Availability of data and materials}

All data generated or analyzed during this study are included in this published article or are available from the corresponding author on reasonable request.

\section{Authors' contributions}

AHP was responsible for the collection, assembly, analysis and interpretation of the data, drifting and writing of the manuscript. SAA, CAS and SAP contributed in the conception and design of the study and the evaluation of the results. ADM and IIP performed the toxicological analysis and the detection of alcohol and drugs in the biological samples. All authors reviewed and critiqued the manuscript, and agreed to the final submission of the manuscript. All authors have read and approved the final version of the manuscript.

\section{Ethics approval and consent to participate}

The Department of Forensic Medicine and Toxicology of the National and Kapodistrian University of Athens is authorized to perform the toxicological investigation of traffic accidents that occur in the major part of the country. 


\section{Patient consent for publication}

Not applicable.

\section{Competing interests}

The authors declare that they have no competing interests.

\section{References}

1. National Highway Traffic Safety Administration (NHTSA): Drunk Driving. 2018. https://www.nhtsa.gov/risky-driving/ drunk-driving. Accessed January, 6, 2019.

2. Ferrari P, Licaj I, Muller DC, Kragh Andersen P, Johansson M, Boeing H, Weiderpass E, Dossus L, Dartois L, Fagherazzi G, et al: Lifetime alcohol use and overall and cause-specific mortality in the European Prospective Investigation into Cancer and nutrition (EPIC) study. BMJ Open 4: e005245, 2014

3. World Health Organization (WHO): Global status report on road safety 2015. Geneva.2015. http://www.who.int/violence_injury_ prevention/road_safety_status/2015/en/.Accessed February, 6, 2019.

4. World Health Organization(WHO):Global status reporton alcohol and health 2014. Geneva, 2014. https://apps.who.int/iris/bitstream/hand le/10665/112736/9789240692763_eng.pdf?sequence=1. Accessed February 16, 2019.

5. Kalsi J, Selander T and Tervo T: Alcohol policy and fatal alcohol-related crashes in Finland 2000-2016. Traffic Inj Prev 19: 476-479, 2018

6. Santoyo-Castillo D, Pérez-Núñez R, Borges G and Híjar M: Estimating the drink driving attributable fraction of road traffic deaths in Mexico. Addiction 113: 828-835, 2018.

7. du Plessis M, Hlaise KK and Blumenthal R: Ethanol-related death in Ga-Rankuwa road-users, South Africa: A five-year analysis. J Forensic Leg Med 44: 5-9, 2016.

8. Sauber-Schatz EK, Ederer DJ, Dellinger AM and Baldwin GT: Vital Signs: Motor Vehicle Injury Prevention - United States and 19 Comparison Countries. MMWR Morb Mortal Wkly Rep 65 672-677, 2016.

9. Tongklao A, Jaruratanasirikul S and Sriplung H: Risky behaviors and helmet use among young adolescent motorcyclists in Southern Thailand. Traffic Inj Prev 17: 80-85, 2016.

10. Clarke DD, Ward P, Bartle C and Truman W: Killer crashes: Fatal road traffic accidents in the UK. Accid Anal Prev 42: 764-770, 2010

11. Vanlaar W, Mainegra Hing M, Brown S, McAteer H, Crain J and McFaull S: Fatal and serious injuries related to vulnerable road users in Canada. J Safety Res 58: 67-77, 2016.

12. Hamnett HJ, Ilett M, Izzati F, Smith SS and Watson KH: Toxicological findings in driver and motorcyclist fatalities in Scotland 2012-2015. Forensic Sci Int 274: 22-26, 2017.

13. Edirisinghe AS, Kitulwatte ID and Senarathne UD: A study into blood alcohol concentration in fatal accidents among vulnerable road users in a tertiary care hospital Sri Lanka. Int J Inj Contr Saf Promot 22: 158-164, 2015.

14. Li G, Brady JE and Chen Q: Drug use and fatal motor vehicle crashes: A case-control study. Accid Anal Prev 60: 205-210, 2013

15. Romano E, Torres-Saavedra P, Voas RB and Lacey JH: Drugs and alcohol: Their relative crash risk. J Stud Alcohol Drugs 75: 56-64, 2014

16. Simonsen K, Linnet K and Rasmussen BS. : Driving under the influence of alcohol and drugs in the eastern part of Denmark in 2015 and 2016: Abuse patterns and trends. Traffic Inj Prev 19: 468-475, 2018.

17. Al-Abdallat IM, Al Ali R, Hudaib AA, Salameh GA, Salameh RJ and Idhair AK: The prevalence of alcohol and psychotropic drugs in fatalities of road-traffic accidents in Jordan during 2008-2014. J Forensic Leg Med 39: 130-134, 2016.

18. Gadegbeku B, Amoros E and Laumon B: Responsibility study: Main illicit psychoactive substances among car drivers involved in fatal road crashes. Ann Adv Automot Med 55: 293-300, 2011.

19. Martin JL, Gadegbeku B, Wu D, Viallon V and Laumon B: Cannabis, alcohol and fatal road accidents. PLoS One 12 e0187320, 2017.

20. Veldstra JL, Brookhuis KA, de Waard D, Molmans BH, Verstraete AG, Skopp G and Jantos R: Effects of alcohol (BAC $0.5 \%$ ) and ecstasy (MDMA $100 \mathrm{mg}$ ) on simulated driving performance and traffic safety. Psychopharmacology (Berl) 222: 377-390, 2012.
21. Brubacher JR, Chan H, Martz W, Schreiber W, Asbridge M, Eppler J, Lund A, Macdonald S, Drummer O, Purssell R, et al: Prevalence of alcohol and drug use in injured British Columbia drivers. BMJ Open 6: e009278, 2016.

22. Athanaselis S, Dona A, Papadodima S, Papoutsis G, Maravelias C and Koutselinis A: The use of alcohol and other psychoactive substances by victims of traffic accidents in Greece. Forensic Sci Int 102: 103-109, 1999.

23. Papadodima SA, Athanaselis SA, Stefanidou ME, Dona AA, Papoutsis I, Maravelias CP and Spiliopoulou CA: Driving under the influence in Greece: A 7-year survey (1998-2004). Forensic Sci Int 174: 157-160, 2008.

24. Papadopoulos IN, Bonovas S, Kanakaris NK, Konstantiadou I, Nikolopoulos G, Konstantoudakis G and Leukidis C: Motor vehicle collision fatalities involving alcohol and illicit drugs in Greece: The need for management protocols and a reassessment of surveillance. Addiction 105: 1952-1961, 2010.

25. Ampanozi G, Kovatsi L, Smyrnakis E, Zaggelidou E, Gavana M, Papadakis N and Benos A: Analysis of fatal motor vehicle collisions: Evidence from Central Macedonia, Greece. Hippokratia 15: 32-36, 2011.

26. O'Neal CL, Wolf CE II, Levine B, Kunsman G and Poklis A: Gas chromatographic procedures for determination of ethanol in postmortem blood using t-butanol and methyl ethyl ketone as internal standards. Forensic Sci Int 83: 31-38, 1996.

27. Costa N, Silva R, Mendonça MC, Real FC, Vieira DN and Teixeira HM: Prevalence of ethanol and illicit drugs in road traffic accidents in the centre of Portugal: An eighteen-year update. Forensic Sci Int 216: 37-43, 2012.

28. Anowar S, Yasmin S and Tay R: Comparison of crashes during public holidays and regular weekends. Accid Anal Prev 51: 93-97, 2013

29. Foster S, Gmel G, Estévez N, Bähler C and Mohler-Kuo M: Temporal patterns of alcohol consumption and alcohol-related road accidents in young swiss men: Seasonal, weekday and public holiday effects. Alcohol Alcohol 50: 565-572, 2015.

30. Furr-Holden CD, Voas RB, Lacey J, Romano E and Jones K: The prevalence of alcohol use disorders among night-time weekend drivers. Addiction 106: 1251-1260, 2011.

31. European Commission: Road safety in the European Union Trends, statistics and main challenges. 2018. https://ec.europa.eu/ transport/road_safety/sites/roadsafety/files/vademecum_2018. pdf. Accessed March 16, 2019.

32. Odero W, Garner P and Zwi A: Road traffic injuries in developing countries: A comprehensive review of epidemiological studies. Trop Med Int Health 2: 445-460, 1997.

33. Brady JE and Li G: Prevalence of alcohol and other drugs in fatally injured drivers. Addiction 108: 104-114, 2013.

34. Bogstrand ST, Larsson M, Holtan A, Staff T, Vindenes V and Gjerde $\mathrm{H}$ : Associations between driving under the influence of alcohol or drugs, speeding and seatbelt use among fatally injured car drivers in Norway. Accid Anal Prev 78: 14-19, 2015.

35. Pelição FS, Peres MD, Pissinate JF, de Paula DM, de Faria M, Nakamura-Palacios EM and De Martinis BS: Predominance of alcohol and illicit drugs among traffic accidents fatalities in an urban area of Brazil. Traffic Inj Prev 17: 663-667, 2016.

36. United Nations Office on Drugs and Crime (UNODC): World Drug Report 2018. United Nations publication. Sales No. E.18.XI.9. 2018. https://www.unodc.org/wdr2018/. Accessed March 6, 2019.

37. Gjerde H, Christophersen AS, Normann PT and Mørland J: Toxicological investigations of drivers killed in road traffic accidents in Norway during 2006-2008. Forensic Sci Int 212: 102-109, 2011.

38. Lloyd L, Wallbank C and Broughton J: A collection of evidence for the impact of the economic recession on road fatalities in Great Britain. Accid Anal Prev 80: 274-285, 2015.

39. Gopaul CD, Singh-Gopaul A, Sutherland JM, Rostant L, Ebi KL and Chadee DD: The epidemiology of fatal road traffic collisions in trinidad and tobago, West Indies (2000-2011). Glob Health Action 9: 32518, 2016.

40. Bénié Bi Vroh J, Tiembre I, Ekra DK, Ano Ama MN, Ka OM, Ncho Dagnan S and Tagliante-Saracino J: Determinants of fatal road traffic injuries in Côte d'Ivoire from 2002 to 2011. Sante Publique 28: 647-653, 2016.

41. Ding Y, Zhou J, Yang J and Laflamme L: Demographic and regional characteristics of road traffic injury deaths in Jiangsu Province, China. J Public Health (Oxf) 39: e79-e87, 2017.

42. Kudryavtsev AV, Nilssen O, Lund J, Grjibovski AM and Ytterstad B: Road traffic crashes with fatal and non-fatal injuries in Arkhangelsk, Russia in 2005-2010. Int J Inj Contr Saf Promot 20: 349-357, 2013. 
43. Mirza FH, Hassan Q and Jajja N: An autopsy-based study of death due to road traffic accidents in metropolis of Karachi. J Pak Med Assoc 63: 156-160, 2013

44. Ramadani N, Zhjeqi V, Berisha M, Hoxha R, Begolli I, Salihu D and Krasniqi P: Public Health Profile of Road Traffic Accidents in Kosovo 2010-2015. Open Access Maced J Med Sci 5: 1036-1041, 2017.

45. Majdan M, Rusnak M, Rehorcikova V, Brazinova A, Leitgeb J and Mauritz W: Epidemiology and patterns of transport-related fatalities in Austria 1980-2012. Traffic Inj Prev 16: 450-455, 2015.

46. Reddy NB, Hanumantha, Madithati P, Reddy NN and Reddy CS: An epidemiological study on pattern of thoraco-abdominal injuries sustained in fatal road traffic accidents of Bangalore: Autopsy-based study. J Emerg Trauma Shock 7: 116-120, 2014

47. Lambert-Bélanger A, Dubois S, Weaver B, Mullen N and Bédard M: Aggressive driving behaviour in young drivers (aged 16 through 25) involved in fatal crashes. J Safety Res 43: 333-338, 2012.

48. Weiss HB, Kaplan S and Prato CG: Analysis of factors associated with injury severity in crashes involving young New Zealand drivers. Accid Anal Prev 65: 142-155, 2014.

49. Khadem-Rezaiyan M, Moallem SR and Vakili V: High-risk behaviors while driving: A population-based study from Iran. Traffic Inj Prev 18: 257-261, 2017.
50. Abayomi O, Babalola OR, Olakulehin OA and Ighoroje M: Drink driving and risky behavior among university students in southwestern Nigeria-Implications for policy development. Traffic Inj Prev 17: 330-335, 2016.

51. Hingson R, Zha W and Smyth D: Magnitude and trends in heavy episodic drinking, alcohol-impaired driving, and alcohol-related mortality and overdose hospitalizations among emerging adults of college ages 18-24 in the United States, 1998-2014. J Stud Alcohol Drugs 78: 540-548, 2017.

52. Kaimila B, Yamashina H, Arai A and Tamashiro H: Road traffic crashes and fatalities in Japan 2000-2010 with special reference to the elderly road user. Traffic Inj Prev 14: 777-781, 2013.

53. Rolison JJ, Hewson PJ, Hellier E and Husband P: Risk of fatal injury in older adult drivers, passengers, and pedestrians. J Am Geriatr Soc 60: 1504-1508, 2012.

54. Zito GA, Cazzoli D, Scheffler L, Jäger M, Müri RM, Mosimann UP, Nyffeler T, Mast FW and Nef T: Street crossing behavior in younger and older pedestrians: An eye- and head-tracking study. BMC Geriatr 15: 176, 2015.

55. Cicchino JB and McCartt AT: Critical older driver errors in a national sample of serious U.S. crashes. Accid Anal Prev 80: 211-219, 2015.

56. Doroudgar S, Chuang HM, Perry PJ, Thomas K, Bohnert K and Canedo J: Driving performance comparing older versus younger drivers. Traffic Inj Prev 18: 41-46, 2017. 